\title{
A PROFISSIONALIZAÇÃO dO AGENTE COMUNITÁRIO NA PERSPECTIVA DA PROMOÇÃO DA SAÚDE
}

\author{
Bruna Muller ${ }^{1}$, Dayana Barradas², Maria Antonia Ramos Costaํ, Mariele da Silva Cambiriba ${ }^{1}$
}

\begin{abstract}
RESUMO: : Este estudo buscou esclarecer, por meio de reflexão de cunho bibliográfico e documental, a importância do agente comunitário de saúde como educador e promotor da saúde na comunidade. Esse profissional adquiriu grande relevância no cenário da assistência primária ao atuar como promotor de saúde capaz de despertar mudanças de hábitos nas famílias e efetivo controle social, fato este apoiado em condições políticas e legais para sua efetivação. Esta reflexão aponta que a postura do agente comunitário de saúde diante das famílias deve ser mais inovadora e reflexiva, promovendo senso crítico e, portanto, ativa diante das situações cotidianas relativas à saúde.
\end{abstract}

PALAVRAS-CHAVE: Saúde da família; Promoção da saúde, Educação em saúde.

\section{THE PROFESSIONALIZATION OF THE COMMUNITY HEALTHCARE ASSISTANT FROM THE PERSPECTIVE OF HEALTH PROMOTION}

\begin{abstract}
This study aimed to clarify, through reflection of a bibliographical and documental nature, the importance of the community healthcare assistant as an educator and health promoter in the community. These professionals have acquired great relevancy in the primary healthcare scenario, by acting as health promoters capable of bringing about changes in habits in families and effective social control, this being supported by political and legal conditions to take place. This reflection indicates that the community healthcare assistant's stance regarding families must be more innovative and reflexive, promoting a critical but active attitude to routine situations related to health.
\end{abstract}

KEYWORDS: Family health; Health promotion; Health education.

\section{LA PROFESIONALIZACIÓN DEL AGENTE COMUNITARIO EN LA PERSPECTIVA DE LA PROMOCIÓN DE LA SALUD}

RESUMEN: Este estudio tuvo el objetivo de aclarar, por medio de reflexión bibliográfica y documental, la importancia del agente comunitario de salud como educador y promotor de la salud en la comunidad. Ese profesional ha adquirido grande relevancia en el campo de la asistencia primaria al actuar como promotor de salud capaz de causar cambios de hábitos en las familias y efectivo control social, hecho apoyado en condiciones políticas y legales para su efectivación. Esta reflexión muestra que la postura del agente comunitario de salud delante de las familias debe ser más innovadora y reflexiva, promoviendo sentido crítico y, por lo tanto, activa delante de las situaciones cotidianas relativas a la salud.

PALABRAS-CLAVE: Salud de la familia; Promoción de la salud, Educación en salud.

${ }^{1}$ Enfermeira.

${ }^{2}$ Enfermeira. Especialista em Saúde Pública e da Família. Professora do Curso de Graduação em Enfermagem da Faculdade Estadual de Educação, Ciência e Letras de Paranavaí - FAFIPA.

${ }^{3}$ Enfermeira. Mestre em Saúde Pública. Professora do Curso de Graduação em Enfermagem da FAFIPA.

Autor correspondente:

Recebido: $18 / 08 / 2010$

Maria Antonia Ramos Costa

Aprovado: 29/08/2011

Faculdade Estadual de Educação, Ciência e Letras de Paranavaí

Rua Prudentópolis, 1390 - 87704-190 - Paranavaí-PR-Brasil

E-mail: mariacosta@sescpr.com.br 


\section{INTRODUÇÃO}

O Programa de Agente Comunitário de Saúde (PACS) decorre de uma medida emergencial para criar oportunidade de emprego para as mulheres, no Ceará em 1987, e contribuir para a queda da mortalidade infantil naquele estado. Com estes objetivos foram desenvolvidas ações de educação em saúde com grande impacto na redução da mortalidade infantil e materna da época ${ }^{(1)}$. Com base nesta experiência, o Ministério da Saúde institucionalizou, em 1991, o PACS com intuito de proporcionar à população brasileira o acesso e a universalização do atendimento à saúde, descentralizando as ações, por meio de visitas domiciliares realizadas por Agente Comunitário de Saúde (ACS) ${ }^{(1-2)}$, e em 1994 criou o Programa Saúde da Família, atualmente Estratégia Saúde da Família (ESF) cujo foco está na atenção às famílias para a construção e consolidação do Sistema Único de Saúde (SUS) por meio da reorientação do modelo assistencial, a partir da atenção básica ${ }^{(3)}$.

As atividades do ACS caracterizam-se por ações de prevenção da doença e promoção da saúde, individuais ou coletivas ${ }^{(4)}$. Contudo, o contexto da promoção de saúde é muito amplo e engloba vários outros conceitos, que visam a um caminho para a melhoria das condições de saúde e de vida da população, apoiando-se no exercício da cidadania ${ }^{(5)}$. Sendo assim, para o profissional de saúde, em especial para o ACS, torna-se imprescindível conhecer e diferenciar o objetivo de prevenção da doença e promoção à saúde.

As inúmeras conceituações disponíveis para a promoção da saúde podem ser reunidas em dois grandes grupos. O primeiro, constituído de atividades dirigidas à transformação dos comportamentos dos indivíduos e focadas nos seus estilos de vida. O segundo grupo parte da constatação do papel protagonista dos determinantes gerais acerca das condições de saúde. Suas atividades estariam mais voltadas ao coletivo de indivíduos e ao ambiente ${ }^{(6)}$.

Neste contexto, discutir o papel do ACS na ESF se torna imprescindível, pois o contato permanente com o individuo, a família e a comunidade permitem que ele estabeleça vínculo, adquirindo autonomia nas ações relativas à resolução de problemas de saúde da sua comunidade.

A partir desta perspectiva, este estudo teve como objetivo refletir sobre promoção de saúde e apresentar a importância do ACS como educador e promotor da saúde no sentido de transformar comportamentos e estilos de vida em prol da melhoria da qualidade de vida da população.

\section{MÉTODO}

Trata-se de uma reflexão de cunho bibliográfico e documental, que utilizou a leitura criteriosa de pesquisas publicadas nos últimos 10 anos identificados nas bases de dados: LILACS (Literatura Latino-Americana e do Caribe em Ciências da Saúde), SciELO (Scientific Electronic Library Online) e Bireme, e da vivência dos autores com a prática profissional em equipe saúde da família. Foram selecionadas fontes documentais, relacionadas ao estudo do ACS que auxiliaram na reconfiguração da profissão e sua interface com a promoção da saúde.

Os descritores utilizados para a seleção bibliográfica foram: Agente Comunitário de Saúde, Educação em saúde, Promoção da saúde e Estratégia Saúde da Família; foram critérios de inclusão pesquisas publicadas entre 2000 e 2010 , com tema adequado ao proposto neste estudo.

\section{RESULTADOS}

Foram identificados 14 pesquisas que atendiam aos critérios de inclusão, os quais estão distribuídos na tabela 1.

A análise dos artigos selecionados permitiu identificar a visão de diferentes pesquisadores quanto ao papel do ACS no contexto de promoção da saúde, fundamentando a discussão proposta pelo trabalho e a seguir apresentada.

Tabela 1-Distribuição de estudos sobre a atuação do importância do ACS como educador e promotor da saúde, 2000-2010. Paranavaí, 2010

\begin{tabular}{lccc}
\hline \multicolumn{1}{c}{ Descritores } & N. & Ano de publicação & Base de dados \\
\hline Agente Comumunitário de Saúde & 5 & $2002,2004,2010$ & SciELO, LILACS \\
Promoção da Saúde & 4 & $2000,2003,2004,2007$ & Bireme, SciELO \\
Educação em Saúde & 2 & 2004,2005 & LILACS, SciELO \\
$\begin{array}{c}\text { Estratégia Saúde da Família } \\
\quad \text { Total }\end{array}$ & 3 & $2004,2007,2008$ & SciELO, Bireme, LILACS \\
\hline
\end{tabular}

Cogitare Enferm. 2012 Jan/Mar; 17(1):171-4 


\section{DISCUSSÃO}

Desde 1991 o ACS está inserido no SUS, seja no PACS, seja na ESF, que em 2006 com a instituição da Portaria 648/GM deixou de ser Programa e passou a ser Estratégia Saúde da Família (ESF) ${ }^{(7)}$. Para exercer a profissão, o ACS deve residir na área da comunidade em que atuar, haver concluído, com aproveitamento, curso de qualificação básica para a formação e o ensino fundamental ${ }^{(4)}$.

Residindo na comunidade em que atua, o ACS tem melhores condições de conhecer os fatores determinantes do processo saúde-doença que mais acomete a população, além de fortalecer o vínculo com a comunidade, a qual pode perceber o ACS como educador e promotor da saúde.

Antes da criação da Lei 10.507 de 10 de junho de 2002, para exercer a profissão de ACS bastava saber ler e escrever; em consequência da grande importância que esses adquiriram no contexto do SUS, os gestores perceberam a necessidade de exigir, como requisito mínimo para a profissão, o ensino fundamental completo ${ }^{(8)}$.

Ainda em relação ao grau de escolaridade há muito a refletir, pois após a implantação da ESF, o papel do ACS foi ampliado, saindo do foco materno-infantil para estender-se à família e à comunidade, exigindo dele novas competências no campo político e social. Desse modo, é necessário que o ACS tenha um grau de escolaridade mais elevado, para dar conta desse novo papel, bem mais complexo e abrangente, principalmente após a criação da Lei 10.507 que trata das suas atribuições, com destaque no "[...] exercício de prevenção e promoção da saúde [...]" e assim, promover saúde se torna um desafio a todos, principalmente para o $\operatorname{ACS}^{(4: 1)}$

Mesmo com a criação da referida Lei, ainda há falha na delimitação das atribuições do ACS, sobrecarregando, muitas vezes, seu trabalho; qualquer ação que deva ser desenvolvida nas famílias e na comunidade é a esse profissional atribuída. Como exemplo, a identificação de crianças fora da escola, a limpeza das caixas d'água para combater o mosquito da Dengue, a monitoração de dermatoses e parasitoses, entre outros, são consideradas atribuições do $\mathrm{ACS}^{(9)}$. Tal fato tem implicação direta no processo inadequado de qualificação, pois este profissional passa a receber diversos micro-treinamentos, fragmentados e de diferentes programas, fora do contexto e sem sequência lógica.

O profissional designado como instrutor supervisor, segundo a portaria ministerial, é o enfermeiro:
A capacitação do ACS deve ocorrer em serviço, de forma continuada, gradual e permanente. Sob responsabilidade do Instrutor - Supervisor, com a participação e colaboração de outros profissionais do serviço local de saúde ${ }^{(9: 5)}$.

Para tanto, o enfermeiro supervisor deve buscar exercer tal capacitação sem sobrecarregar o ACS de tarefas e que possam dificultar o exercício de sua principal função: prevenir doenças e promover saúde mediante visitas domiciliares. Ressalta-se que o diálogo entre o enfermeiro e o ACS é imprescindível por promover discussões acerca de dificuldades e facilidades relacionadas ao seu trabalho. A verbalização de tais situações pode apresentar-se como um instrumento auxiliar no enfrentamento de problemas e na articulação de ações que garantam eficácia e eficiência no desempenho das atividades deste profissional ${ }^{(10)}$.

Em se tratando de promoção da saúde, embora o termo tenha sido inicialmente usado para caracterizar a atenção da medicina preventiva, seu significado foi mudando. Recentemente representar um enfoque político e técnico em torno do processo saúde-doença-cuidado. A Carta de Ottawa, um dos documentos fundadores da promoção da saúde, destaca que o termo prevenção está associado a um conjunto de valores, como: "qualidade de vida, saúde, solidariedade, equidade, democracia, cidadania, desenvolvimento, participação e parceria"(7:165). Ressalta também que:

Para se promover saúde necessita-se uma combinação de estratégias: ações do Estado (políticas públicas saudáveis), da comunidade (reforço da ação comunitária), de indivíduos (desenvolvimento de habilidades pessoais), do sistema de saúde (reorientação do sistema de saúde) e de parcerias intersetoriais. Sempre trabalhando com a idéia de responsabilização múltipla, seja pelos problemas, seja pelas soluções propostas para os mesmos ${ }^{(7: 165-6)}$.

Analisando a combinação de estratégias já citadas, observa-se que essas são complementares para a promoção da saúde. No que diz respeito à elaboração de políticas públicas saudáveis, os gestores pactuam continuamente ações que visa a promoção da saúde, como por exemplo, em 2006 o Pacto pela Vida e no mesmo ano a criação da Política Nacional de Promoção da Saúde. Contudo, o esforço na construção de um modelo de atenção à saúde que priorize ações de melhoria da qualidade de vida dos sujeitos e coletivos torna-se vão se não houver um processo de empoderamento ${ }^{(6)}$. $\mathrm{O}$ empoderamento fundamenta-se no exercício da cidadania é um processo de capacitação que habilita a população a exercer o controle de seu destino, promo- 
vendo a melhoria das suas condições de vida e saúde, a partir da conscientização dos determinantes dos problemas ou da formação do pensamento crítico $^{(6)}$.

Diante disso, vale ressaltar que os profissionais que integram a ESF têm como atribuição comum "promover a mobilização e a participação da comunidade, buscando efetivar o controle social"(9:23). Sendo assim, o trabalho do ACS como educador para a promoção a saúde, tem fundamental importância, pois

\footnotetext{
busca articular saberes técnicos e populares, mobilizar recursos institucionais e comunitários, públicos e privados, de diversos setores, para o enfrentamento e a resolução dos problemas de saúde. Nessa concepção, a população assume um papel ativo no processo de construção das práticas sanitárias para o enfrentamento de diversos problemas e necessidades de saúde ${ }^{(10: 237)}$.
}

Assim, o ACS, mantendo contato permanente com as famílias, estabelece o respeito, o vínculo e a autonomia, o que oportunizará a educação da população para enfrentar, de forma ativa, seus problemas e contribuirá para a promoção da saúde.

\section{CONSIDERAÇÕES FINAIS}

Constatou-se a complexidade da conceituação de promoção da saúde, revelando que promover saúde é um grande desafio para todos. Neste contexto, o ACS contribui para o processo de transformação social e promoção da saúde. No entanto, seu processo de ensino aprendizagem, como dos demais componentes da equipe saúde da família, deve ser inovador, reflexivo e crítico, centrado no desenvolvimento de suas competências, evitando desestrutura, fragmentação e insuficiência de informações.

Assim, espera-se que este estudo instigue enfermeiros e ACS a refletirem sobre a necessidade de atuarem como promotores de saúde, articulando com gestores estratégias que promovam educação em saúde à população, sob a perspectiva de promover a qualidade de vida.

Conclui-se que as mudanças ocorridas na saúde perpassam por aprimoramento de estratégias de ensino e aprendizagem que se estendem e se reconfiguram nos diversos profissionais da equipe de saúde. O ACS é um desses profissionais, sua trajetória profissional avança na medida em que as diversas acepções do termo promoção da saúde se ampliam para o atual contexto social. Nesta perspectiva, o ACS atua como promotor da saúde, papel este respaldado por instrumentos legais, norteadores das políticas públicas de saúde vigentes, e que expressam concepções de uma determinada época.

\section{REFERÊNCIAS}

1. Tomaz JB. O agente comunitário de saúde não deve ser um “super-herói”. Interface. 2002;10(6):75-94.

2. Levi FM, Mattos PE, Tomitta NE. Programa de agentes comunitários de saúde: a percepção de usuários e trabalhadores da saúde. Cad. saude publica. 2004;20(1):197-203.

3. Alves VS. Um modelo de educação em saúde para o programa saúde da família: pela integralidade da atenção e reorientação do modelo assistencial. Interface. 2005;9(16):39-52.

4. Brasil. Lei n. 10.507, de 10 de julho de 2002. Cria a profissão de Agente Comunitário de Saúde e dá outras providências. Diário Oficial da República Federativa do Brasil, Brasília, 11 jul. 2002. Seção 1:1.

5. Bydlowski CR, Westphal MF, Pereira IM. Promoção da saúde. Porque sim e porque ainda não! Saúde soc. 2004;13(1):14-24.

6. Buss PM. Promoção de saúde e qualidade de vida. Cienc. saude colet. 2000;5(1):163-77.

7. Ministério da Saúde (BR). Portaria n. 648/GM, de 28 de março de 2006: aprova a Política Nacional de Atenção Básica. Diário Oficial da União [Internet] 28 mar 2006 [acesso em 15 mar2008]. Disponível: http://dtr2001. saude.gov.br/sas

8. Ministério da Saúde (BR). Portaria n. 1.886/GM, de 18 de dezembro de 1997: Norma e Diretrizes do Programa de Agentes Comunitários de Saúde e do Programa de Saúde da Família. Diário Oficial da União [Internet]. [acesso em 15 mar 2008]. Disponível: http://www. faurgs.ufrgs.br/concursos/PMC0105/portaria1886.pdf

9. Brand CI, Antunes RM, Fontana RT. Satisfações e insatisfações no trabalho do agente comunitário de saúde. Cogitare enferm. 2010;15(1):40-7.

10. Chiesa AM, Nascimento DDG, Braccialli LAD, Oliveira MAC, Ciampone MHT. A formação de profissionais da saúde: aprendizagem significativa à luz da promoção da saúde. Cogitare enferm. 2007;12(2):236-40. 